\title{
RECURSOS DE INVESTIMENTOS COM OBRAS E INSTALAÇÕES DOS ESTADOS BRASILEIROS E DO DISTRITO FEDERAL: ÍNDICE DE DESEMPENHO (2013 - 2015)
}

\author{
Maurício Corrêa da Silva \\ UFRN - Professor \\ Brasil
}

Fábia Jaiany Viana de Souza

IFRN - Contadora

Brasil

José Dionísio Gomes da Silva

UFRN - Professor

Brasil

Adilson de Lima Tavares

UFRN - Professor.

Brasil

Anailson Márcio Gomes

UFRN - Professor

Brasil

Data de submissão: 12/07/2017

Data de aceite:05/02/2018

\section{RESUMO}

O objetivo desta investigação é elaborar um índice de desempenho dos Estados Brasileiros e do Distrito Federal na alocação de recursos em obras e instalações com os valores destinados para as despesas de investimentos na execução orçamentária de 2013 a 2015, com a utilização de métrica quantitativa. Foi utilizado o método de pesquisa empírico-analítico, com suporte das Teorias dos Stakeholders e da Escolha Pública. Os dados sobre $\mathrm{o}$ indicador de comprometimento dos recursos de despesas de investimentos em obras e instalações foram extraídos do sítio eletrônico da Secretaria do Tesouro Nacional - STN. Os resultados revelaram com base no ranking do Índice de Desempenho de Alocação de Recursos com Obras e Instalações (IDROI), que os Estados de Alagoas, Paraíba e Mato Grosso ficaram nas primeiras posições (foram mais eficientes) e os Estados de Rondônia, Rio Grande do Sul e Paraná ficaram nas últimas posições (menos eficientes). Como principais stakeholders, no processo de avaliação de resultados da gestão pública por indicador e índice de desempenho, destacam os 
cidadãos, os governos estaduais e distrital (gestores públicos) e os órgãos de fiscalização (Controladorias, Tribunais de Contas dos Estados e do Distrito Federal).

Palavras-chave: Índice de desempenho. Indicador de obras e instalações. Mensuração quantitativa. Estados e Distrito Federal.

\title{
INVESTMENT RESOURCES WITH CONSTRUCTION WORKS AND FACILITIES OF THE BRAZILIAN STATES AND OF THE FEDERAL DISTRICT: PERFORMANCE INDEX (2013-2015)
}

\begin{abstract}
The objective of this investigation is to formulate a performance index of the Brazilian States and of the Federal District in the allocation of resources in construction works and facilities with the values directed to the investment expenditures in the budgetary execution from 2013 to 2015, with the use of quantitative metrics. It was used the empirical-analytical research method, with support of the Stakeholder and the Public Choice Theories. The data related to the indicator of commitment of the investment expenditure resources in construction works and facilities were extracted from the electronic website of the National Treasury Bureau (STN). The results revealed, based on the ranking of the Index of Performance of Allocation of Resources with Construction Works and Facilities (IDROI), that the States of Alagoas, Paraíba and Mato Grosso were in the first positions (they were more efficient) and the States of Rondônia, Rio Grande do Sul and Paraná were in the last positions (less efficient). As main stakeholders, in the process of assessment of results of the public management by indicator and performance index, it stands out the citizens, the state and district governments (public managers) and the inspection authorities (Controllerships, Courts of Accounts of the States and of the Federal District).
\end{abstract}

Keywords: Performance index. Indicator of construction works and facilities. Quantitative measurement. States and Federal District.

\section{INTRODUÇÃO}

Os gastos públicos, caracterizados pelo resultado das contas públicas, são a evidenciação das políticas de gestão efetuadas pelos governantes. A execução orçamentária da despesa por funções de governo (legislativa, judiciárias, saúde, educação, saneamento etc.), representa os resultados decorrentes das decisões dos gestores de diferentes ideologias partidárias (mudanças de governo), do cumprimento dos limites obrigatórios e constitucionais (restrições ao poder discricionário no orçamento) dos gastos, das mudanças de orientação dos instrumentos de planejamento do setor público (Plano Plurianual; Lei de Diretrizes Orçamentárias e Lei Orçamentária Anual). Enfim, representam a realidade das aplicações dos recursos em prol da sociedade (SILVA; SILVA, 2017).

As demonstrações contábeis do setor público assumem papel de relevante importância, não apenas pela imperiosidade da lei, mas também como instrumento de 
gestão pública. A utilização de índices na análise de balanços, seja na área pública, seja na privada, envolve a aplicação de cálculos de quocientes que relacionam um conjunto de valores expressos nas demonstrações contábeis (SOARES et al., 2011).

Para Bortoluzzi et al. (2011), a técnica de análise das demonstrações contábeis é uma forma de avaliar o desempenho econômico-financeiro, com o objetivo de apresentar aos gestores das organizações informações que auxiliem no processo de tomada de decisão e que os índices contábeis considerados tradicionais são divididos, centralmente, em três: índices de liquidez (capacidade de pagamento), rentabilidade (situação econômica) e estrutura de capital (situação financeira).

As técnicas mais citadas nas análises das demonstrações contábeis públicas incluem indicadores/índices para avaliar a gestão financeira: relação entre o ativo financeiro e o passivo financeiro (MELLO; SLOMSKI, 2007; SOARES et al., 2011); a gestão orçamentária: quocientes do resultado e do equilíbrio orçamentário (SILVA et al., 2013) e indicadores para avaliar os demonstrativos incluídos pela Lei de Responsabilidade Fiscal (BRASIL, 2000a): índice de comprometimento da receita corrente líquida com a despesa de pessoal; índice de amortização de dívidas em relação à receita corrente líquida (ANDRADE, 2007), dentre outros.

Zucatto et al. (2009) esclarecem que os indicadores são instrumentos importantes para controle da gestão não apenas na administração privada, mas também e principalmente na administração pública, por aumentarem a transparência na gestão e facilitarem o diálogo entre os mais diversos grupos sociais organizados.

No caso das obras e instalações executadas em proveito da comunidade pelos gestores públicos, nesta investigação, o indicador do comprometimento dos recursos de despesas com investimento em obras e instalações visa identificar o quanto dos recursos orçamentários das despesas de capital do elemento de despesa denominado de investimentos foi destinado para atender diretamente as obras e instalações.

Diante do acima exposto, surge a seguinte questão de pesquisa: Qual foi o desempenho dos Estados Brasileiros e do Distrito Federal na alocação de recursos em obras e instalações com os valores destinados para as despesas de investimentos na execução orçamentária de 2013 a 2015? Assim, o objetivo desta investigação é elaborar um índice de desempenho dos Estados Brasileiros e do Distrito Federal na alocação de recursos em obras e instalações com os valores destinados para as despesas de 
investimentos na execução orçamentária de 2013 a 2015, com a utilização de métrica quantitativa

A investigação justifica-se pela relevância que a estratégia da pesquisa de avaliação de resultados tem para os cidadãos e para os gestores públicos. Os cidadãos poderão ser motivados a buscarem informações sobre o desempenho administrativo dos seus gestores. Neste sentido, Diniz, Macedo e Corrar (2012) argumentam que a população brasileira não tem essa cultura e que a informação que está mais em evidência diz respeito às denúncias e à apuração de condutas relacionadas com a corrupção. Os gestores públicos poderão incluir em suas rotinas a utilização de indicadores. Zucatto et al. (2009) ensina que um indicador pode ser definido como um parâmetro que medirá a diferença entre a situação desejada e a situação atual, ou seja, ele indicará um problema.

Ademais, estudos correlatos poder ser motivados com os resultados desta investigação, tanto na utilização de avaliação de desempenho a partir de indicadores, bem como na utilização da métrica quantitativa utilizada.

A pesquisa está amparada pelas Teorias dos Stakeholders e Escolha Pública, além de revisitar conceitos de finanças públicas e para atingir o objetivo proposto, este artigo está dividido em cinco seções. Após esta introdução, a seção dois traz a revisão da literatura. A seção seguinte os procedimentos metodológicos. A quarta seção mostra os resultados da pesquisa e discussões. A quinta seção trata das considerações finais.

\section{REVISÃO DA LITERATURA}

\subsection{Recursos Públicos}

O Estado necessita para atender as obrigações constitucionais, segundo Jund (2008), obter as receitas públicas; criar o crédito público (endividamento); planejar e gerir o orçamento público e despender recursos (despesa pública). De acordo com Vieira (2009), o Estado é dotado de funções que vão desde a esfera financeira e estrutural até aspectos sociais e econômicos.

A Administração Pública é o instrumento de que dispõe o Estado para atingir os seus objetivos. Matias-Pereira (2009) ensina que o Estado existe fundamentalmente para realizar o bem-comum. Marques (2003) esclarece que a atividade econômica de um ente 
público, tendente a afetar bens à satisfação de necessidades que lhe estão confiadas é designada por Finanças Públicas.

A política do setor público, tanto como a do setor privado, pode ser errada e ineficiente; e o propósito básico do estudo das finanças públicas é pesquisar de que forma a eficácia da formulação e aplicação das políticas públicas pelo setor público pode ser melhorada. A necessidade de um setor público é necessária para guiar, corrigir e suplementar o sistema de mercado, que não pode desempenhar sozinha todas as funções econômicas (MUSGRAVE; MUSGRAVE, 1980). Para Matias-Pereira (2012a), os governos são necessários à sociedade, tanto do ponto de vista institucional como organizacional.

As finanças públicas buscam prover, por meio das autoridades públicas, os bens e serviços públicos ou coletivos, que as pessoas não podem adquirir em pequenas quantidades, como educação, saúde pública, justiça, segurança pública, entre outros, e a maneira pela qual são financiados. Os ingressos públicos responsáveis pelo financiamento dos gastos do Estado provêm dos impostos, atividade produtiva do Estado e o do crédito ou empréstimos (MATIAS-PEREIRA, 2006).

Os recursos necessários para a administração pública cumprir seus objetivos são denominados de receitas. Silva (2009) esclarece que a receita pública é o conjunto dos recursos ou rendas que o Estado dispõe entregues através da contribuição da coletividade para fazer face as suas necessidades.

A receita pública é classificada nas categorias econômicas receitas correntes (receita tributária, de contribuições, patrimonial etc.), destinadas a atender as despesas classificáveis em despesas correntes e receitas de capital (operações de crédito, alienação de bens etc.), destinadas a atender as despesas de capital.

A Lei ${ }^{\circ}$. 4.320 de 17 de março de 1964 (BRASIL, 1964) não define as despesas, apenas as classifica em categorias econômicas (art. 12) em: despesas correntes (despesas de custeio e transferências correntes) e despesas de capital (investimentos, inversões financeiras e transferências de capital) e para atender ao disposto no Parágrafo $1^{\circ}$. do art. 50 da Lei de Responsabilidade Fiscal - LRF (BRASIL, 2000a), foram criadas as Despesas Correntes Intra-orçamentárias e as Despesas de Capital Intra-orçamentárias.

A classificação da despesa orçamentária pode ser entendida a partir da Portaria Conjunta da Secretaria do Tesouro Nacional e da Secretaria de Orçamento Federal - 
STN/SOF n ${ }^{\circ} 3$, de15 de outubro de 2008 (BRASIL, 2008). A despesa é classificada em cinco níveis: $1^{\circ}$ nível: categoria econômica; $2^{\circ}$ nível: grupo de natureza de despesa; $3^{\circ}$ nível: modalidade de aplicação; $4^{\circ}$ nível: elemento da despesa e $5^{\circ}$ nível: desdobramento do elemento da despesa (facultativo). O Quadro 1 demonstra como é realizada essa classificação.

\section{Quadro 1 - Classificação da despesa orçamentária}

\begin{tabular}{|c|c|}
\hline \multicolumn{2}{|r|}{ Categoria Econômica } \\
\hline 1. Despesas Correntes & 2. Despesas de Capital \\
\hline \multicolumn{2}{|r|}{ Grupo de Natureza da Despesa } \\
\hline \multirow{3}{*}{ 1. Despesas Correntes } & 1. Pessoal e Encargos Sociais \\
\hline & 2. Juros e Encargos da Dívida \\
\hline & 3. Outras Despesas Correntes \\
\hline \multirow{3}{*}{ 2. Despesas de Capital } & 4. Investimentos \\
\hline & 5. Inversões Financeiras \\
\hline & 6. Amortização da Dívida \\
\hline \multicolumn{2}{|r|}{ Elemento da Despesa } \\
\hline $\begin{array}{l}\text { 1. Pessoal e Encargos } \\
\text { Sociais }\end{array}$ & $\begin{array}{l}\text { 01 - Aposentadorias e Reformas; } 03 \text { - Pensões; } 04 \text { - Contratação por } \\
\text { Tempo Determinado; 05 - Outros Benefícios Previdenciários; } 11 \text { - } \\
\text { Vencimentos e Vantagens Fixas - Pessoal Civil; 13 - Obrigaçôes } \\
\text { Patronais; } 16 \text { - Outras Despesas Variáveis - Pessoal Civil; } 17 \text { - Outras } \\
\text { Despesas Variáveis - Pessoal Militar. }\end{array}$ \\
\hline $\begin{array}{l}\text { 2. Juros e Encargos da } \\
\text { Dívida }\end{array}$ & $\begin{array}{l}21 \text { - Juros sobre a Dívida por Contrato; } 22 \text { - Outros Encargos sobre a } \\
\text { Dívida por Contrato; } 23 \text { - Juros, Deságios e Descontos da Dívida } \\
\text { Mobiliária; } 24 \text { - Outros Encargos sobre a Dívida Mobiliária. }\end{array}$ \\
\hline $\begin{array}{l}\text { 3. Outras Despesas } \\
\text { Correntes }\end{array}$ & $\begin{array}{l}30 \text { - Material de Consumo; } 32 \text { - Material de Distribuição Gratuita; } 33 \text { - } \\
\text { Passagens e Despesas com Locomoção; } 35 \text { - Serviços de Consultoria; } 36 \text { - } \\
\text { Outros Serviços de Terceiros - Pessoa Física; } 37 \text { - Locação de Mão-de- } \\
\text { Obra; } 38 \text { - Arrendamento Mercantil; } 39 \text { - Outros Serviços de Terceiros - } \\
\text { Pess. Jurídica. }\end{array}$ \\
\hline 4. Investimentos & $\begin{array}{l}20 \text { - Transferências; } 90 \text { - Aplicações diretas (30 - Material de Consumo; } \\
39 \text { - Serviços de Terceiros; } 51 \text { - Obras e Instalações; } 52 \text { - Equipamentos e } \\
\text { Material Permanente; } 61 \text { - Aquisição de Imóveis; } 92 \text { - Despesas de } \\
\text { Exercícios Anteriores; } 93 \text { - Indenizções e Restituições). }\end{array}$ \\
\hline 5. Inversões Financeiras & $\begin{array}{l}61 \text { - Aquisição de Imóveis; } 63 \text { - Aquisição de Títulos de Crédito; } 64 \text { - } \\
\text { Aquisição de Títulos Representativos de Capital já Integralizado. }\end{array}$ \\
\hline 6. Amortização da Dívida & $\begin{array}{l}71 \text { - Principal da Dívida Contratual Resgatado; } 72 \text { - Principal da Dívida } \\
\text { Mobiliária Resgatado; } 73 \text { - Correção Monetária ou Cambial da Dívida } \\
\text { Contratual Resgatada. }\end{array}$ \\
\hline
\end{tabular}

Fonte: Portaria Conjunta STN/SOF nº 3, de 15 de outubro de 2008 (BRASIL, 2008) - adaptado.

Observa-se no Quadro 1 que as despesas de capital possuem três grupos de natureza de despesa (investimentos, inversões financeiras e amortização da dívida). As despesas de investimentos possuem duas modalidades de aplicação (transferências e aplicações diretas). As aplicações diretas atendem despesas com aquisições de material de consumo; prestação de serviços de terceiros; obras e instalações; equipamentos e material permanente; aquisição de imóveis; despesas de exercícios anteriores; 
indenizações e restituições etc. $\mathrm{O}$ foco desta investigação se refere a relação dos recursos alocados nas despesas de investimentos e as aplicações em obras e instalações.

\subsection{Avaliações de desempenho do setor público}

Os resultados ou desempenho de um dado programa são aferidos através de indicadores que medem os graus, as quantidades e os níveis de qualidade com que as metas programáticas foram cumpridas (DRAIBE, 2001). A execução orçamentária de um programa é monitorada durante a sua implementação e avaliada ex ante e ex post (RAMOS; SCHABBACH, 2012).

Para o Tribunal de Contas da União - TCU (BRASIL, 2000b), a utilização de indicadores de desempenho para aferir os resultados alcançados pelos administradores é uma metodologia que está relacionada ao conceito de gerenciamento voltado para resultados (results oriented management - ROM). Esse conceito tem sido adotado nas administrações públicas de diversos países, especialmente nos de cultura anglo-saxônica (Estados Unidos da América, Austrália, Reino Unido). A expressão indicador de desempenho é também normalmente utilizada no sentido de medição de desempenho (BRASIL, 2000b).

Ainda de acordo com o TCU, informações sobre desempenho são essencialmente comparativas e um conjunto de dados isolados não diz nada a respeito do desempenho de uma entidade. Devem ser feitas comparações com metas ou padrões preestabelecidos, ou realizada uma comparação com os resultados atingidos em períodos anteriores, obtendo-se assim uma série histórica para análise de desempenho.

Segundo o Ministério do Planejamento, Orçamento e Gestão - MPOG (BRASIL, 2009), a palavra desempenho é um termo sujeito a inúmeras variações semânticas e conceituais e segundo uma abordagem abrangente, o desempenho pode ser 
compreendido como esforços empreendidos na direção de resultados a serem alcançados.

O desempenho é um conceito multifacetado que vem sendo explorado por uma variedade de campos do conhecimento como Contabilidade, Estratégia, Recursos Humanos, Produção e Gestão de Operações, Marketing, Comportamento Organizacional e Gestão Estratégica (FRANCO-SANTOS; LUCIANETTI; BOURNE, 2012).

Observa-se com base nas afirmações do Tribunal de Contas da União (BRASIL, 2000b), do Ministério do Planejamento, Orçamento e Gestão - MPOG (BRASIL, 2009) e de Franco-Santos, Lucianetti e Bourne (2012) que os termos "avaliação de desempenho", “indicadores de desempenho" e "medição de desempenho" podem ser considerados como sinônimos, haja vista a existência de variações semânticas e conceituais multifacetadas do termo desempenho.

A avaliação de desempenho para Helden, Johnsen e Vakkuri (2008) é entendida como um instrumento para indicar eficiência, eficácia e equidade no contexto do setor público. É utilizada principalmente para aumentar a racionalidade na tomada de decisão nas organizações, além de auxiliar na prestação de contas, no planejamento e controle.

Para Harrison, Rouse e De Villiers (2012), na perspectiva da Teoria dos Stakeholders a prestação de contas e a medição de desempenho pode e deve ser utilizada no setor público. Como exemplo, no contexto escolar pode ser usado para identificar grupos de interessados que influenciam a criação de objetivos estratégicos. Isso inclui alunos, pais, o público em geral, potenciais empregadores de estudantes, os contribuintes, as comunidades adjacentes às escolas, professores, demais funcionários 
das escolas, gestores escolares, comitês escolares, conselhos escolares de curadores, governadores escolares, o departamento de educação e o governo.

Ainda de acordo com os referidos autores, a aplicação da abordagem a outras organizações do setor público ajuda os gestores identificar a finalidade da avaliação de desempenho, o principal interessado, o seu principal objetivo para a organização, e os indicadores de desempenho relevantes relacionados com esse objetivo. Os gestores também poderão abordar, de forma explícita, como as necessidades de outras partes interessadas podem ser cumpridas (HARRISON; ROUSE; DE VILLIERS, 2012).

O principal marco da Teoria dos Stakeholders tem normalmente sido atribuído à obra de Robert Edward Freeman de 1984, quando publicou seu livro de referência e desde então vários ensaios foram publicados com o objetivo de compor o mosaico desta teoria. Na Inglaterra, esta abordagem foi introduzida pelo Partido Trabalhista em 1997, com o objetivo de tornar a administração pública mais participativa, convidando a sociedade a participar de seus processos decisórios (GOMES, 2006). Para Mcwilliams e Siegel (2001), o trabalho de Freeman é tido como seminal na fundamentação da Teoria dos Stakeholders.

A análise da Teoria dos Stakeholders, para Freeman et al. (2010), no processo de políticas públicas é útil para mapear os grupos constituintes, a estrutura de poder, as redes de políticas e a comunidade. Neste sentido, pode ser usada para identificar o potencial de cada parte interessada em controlar o grupo, formar coalização, identificar o poder relativo etc.

Para Connolly e Hyndman (2013), a Teoria dos Stakeholders pode ser ligada a temas em contabilidade e accountability. $\mathrm{O}$ argumento central proposto por Freeman era que as organizações envolvidas com as partes interessadas numa base de confiança e 
cooperação mútua, iriam construir legitimidade e reputação que lhes daria uma vantagem competitiva sobre os rivais.

Já a Teoria da Escolha Pública, segundo Pereira (1997), foi escrita por economistas e um cientista político (origem mais recente da teoria), entre as décadas de cinquenta e sessenta: Kenneth Arrow em 1951, Duncan Black em 1958, Anthony Downs em 1957, Mancur Olson em 1965, William Riker, James Buchanan e Gordon Tullock em 1962. Neste contexto, Musgrave e Musgrave (1980) esclarecem que a maximização do voto foi esboçada pelo economista Joseph Schumpeter e devolvido por Anthony Downs: o político maximiza os seus votos de maneira a manter no poder e o eleitor maximiza os benefícios líquidos que ele obtém dos gastos governamentais em relação aos gastos que ele incorre em função da tributação.

Os governos se envolvem em ciclos político-econômicos caracterizados pelo aumento da despesa pública em período pré-eleitoral, seguidos por tensões inflacionárias e políticas restritivas no período pós-eleitoral. Tais situações são resultantes do processo democrático em si e não de a natureza particular da política econômica. Assim, pela Teoria da Escolha Pública as regras do jogo do processo democrático é que determinam as políticas e não (apenas) a especificidade do partido do governo (PEREIRA, 1997).

O principal objetivo da Teoria da Escolha Pública é o de aplicar um método da ciência econômica a um objeto que tradicionalmente tem sido considerado no âmbito da ciência política: grupos de interesse, partidos políticos, processo eleitoral, análise da burocracia, escolha parlamentar e análise constitucional (PEREIRA, 1997).

Pereira (1997) esclarece também, que a Teoria da Escolha Pública foi, ao longo das últimas décadas, a principal crítica teórica de outra corrente (essa essencialmente 
econômica) que fundamenta a intervenção do Estado na economia - a economia do bem-estar (welfare economics). Enquanto a economia do bem-estar centrava na análise dos fracassos de mercado que justificavam a intervenção corretora do Estado, a Teoria da Escolha Pública veio clarificar os fracassos do governo e os limites da intervenção desse mesmo Estado.

$\mathrm{Na}$ literatura encontram-se pesquisas realizadas (FOUCAULT; FRANÇOIS, 2005; FOUCAULT; MADIES; PATY, 2008; AIDT; VEIGA; VEIGA, 2011; ABBOTT; JONES, 2013), na ótica da Teoria da Escolha Pública que destacam o comportamento oportunista dos gastos dos governos por ocasião das eleições (antes, durante e depois).

Foucault e François (2005) demonstraram por pesquisa empírica que as decisões de governo locais (91 cidades francesas mais populosas, avaliadas no período de 1977 a 2001) são influenciadas pela agenda política. As despesas operacionais e de capital aumentaram em anos eleitorais substancialmente e, em menor medida, nos anos anteriores às eleições o que prova a existência de um ciclo político-econômico oportunista. Em contraste, houve uma diminuição das despesas, independentemente da sua natureza, durante o ano seguinte ao da eleição. Isso inverte a presença de um ciclo de negócios político-partidária.

Foucault, Madies e Paty (2008) concluíram com evidências empíricas que os governos locais (municipais) da França apresentaram comportamento oportunista com aumentos da todas as categorias de despesas públicas em períodos pré-eleitorais. Concluíram também, que as despesas correntes em matéria de emprego temporário são susceptíveis de serem utilizadas para evitar problemas de coesão social nas cidades analisadas. 
Os resultados empíricos divulgados na pesquisa de Aidt, Veiga e Veiga (2011) realizados em municípios portugueses apoiaram claramente a hipótese de que o oportunismo compensa como maiores gastos no ano eleitoral, quando comparado com o prazo médio de eleição ou, simplesmente em euros per capita. O oportunismo também será maior quando o titular concorre para a reeleição, quando ele pertence a um partido de esquerda, e quando há aumentos nas transferências de capital do governo central no ano eleitoral.

Abbott e Jones (2013) ao analisarem as despesas pró-cíclicas por diferentes níveis de governo (20 países da Organização para a Cooperação e Desenvolvimento Econômico - OCDE entre 1995 e 2006), sob a ótica da Teoria da Escolha Pública, verificaram o impacto que a distribuição do poder fiscal em transferências intergovernamentais exerce como incentivos eleitorais em todos os ramos do governo sobre o padrão de ciclicidade em todas as categorias de despesas (por exemplo, corrente e investimentos em defesa, educação, segurança social e outros itens de linha orçamental).

Depreende-se com base na Teoria dos Stakeholders a importância da medição/avaliação de resultados no setor público, bem como a identificação dos principais stakeholders no processo de avaliação de políticas públicas: identificação do potencial das principais partes interessadas. A Teoria da Escolha Pública auxilia nas avaliações de gastos nos ciclos político-econômicos e nos fracassos do governo na intervenção na economia, além de avaliar os interessados na política. Ao evidenciar o desempenho dos gestores com o indicador do comprometimento dos recursos de despesas com investimento em obras e instalações, as teorias da Escolha Pública e dos Stakeholders poderão ser utilizadas para identificar, respectivamente, gastos em ciclos 
político-econômicos e as principais partes interessadas (stakeholders) e suas posições na gestão pública.

\section{PROCEDIMENTOS METODOLÓGICOS}

\subsection{Estratégia da pesquisa e caracterizações do método, população, variáveis e critério de avaliação}

Esta investigação utiliza a estratégia da pesquisa de avaliação de resultados. Para Martins e Theóphilo (2009), essa é uma estratégia empírica aplicada para avaliar programas, projetos, políticas etc. O método de pesquisa utilizado é o empírico-analítico (arquivo/empirista - banco de dados) que corresponde à utilização de técnica de coleta, tratamento e análise de dados com métricas quantitativas. Matias-Pereira (2012b) esclarece que nesse método, o processo de validação da prova científica é feito por meio de testes dos instrumentos, graus de significância e sistematização das definições operacionais.

A população é constituída de todos os Estados Brasileiros e o Distrito Federal (Tabela 3). Não há amostra. Para compor o índice de desempenho, foram escolhidas duas variáveis (despesas com obras e instalações e despesas de investimentos) representadas pelo indicador de comprometimento dos recursos de despesas de investimentos em obras e instalações conforme constam no Quadro 2. O indicador relativiza as diferenças existentes entre os Estados e o Distrito Federal para calcular o desempenho em relação aos recursos disponibilizados nos exercícios financeiros de 2013 a 2015 (Tabela 3). O indicador representa a forma com que cada entidade fez a alocação de seus recursos com obras e instalações em relação ao total das despesas de seus investimentos (Quadro 1).

O Quadro 2 apresenta as variáveis definidas para calcular o desempenho.

Quadro 2 - Definição de variáveis (indicador de comprometimento dos recursos de despesas de investimentos em obras e instalações)

\begin{tabular}{|c|l|l|}
\hline Indicador & \multicolumn{1}{|c|}{ Composição do Indicador } & \multicolumn{1}{|c|}{ Finalidade } \\
\hline OIN / INV & Despesas com Obras e Instalações - OIN (despesas orçamentárias & Comprometimento \\
& com estudos e projetos; início, prosseguimento e conclusão de obras; & dos recursos de \\
& pagamento de pessoal temporário não pertencente ao quadro da & Despesas com \\
& entidade e necessário à realização das mesmas; pagamento de obras & Investimento em \\
& contratadas; instalações que sejam incorporáveis ou inerentes ao & Obras e \\
& imóvel, tais como: elevadores, aparelhagem para ar condicionado & Instalações \\
& central, etc.) / Despesas de Investimentos - INV (despesas & \\
\hline
\end{tabular}




\begin{tabular}{|l|l|l|}
\hline & $\begin{array}{l}\text { orçamentárias com o planejamento e a execução de obras, inclusive } \\
\text { com a aquisição de imóveis considerados necessários à realização } \\
\text { destas últimas, e com a aquisição de instalações, equipamentos e } \\
\text { material permanente, material de consumo; serviços de consultoria, } \\
\text { transferências à União e a Municípios, despesas de exercícios } \\
\text { anteriores, indenizações e restituições). }\end{array}$ & \\
\hline
\end{tabular}

Fonte: Portaria Conjunta STN/SOF nº 3, de 15 de outubro de 2008 (BRASIL, 2008) - adaptado.

O resultado do indicador do Quadro 2 é do tipo: quanto maior, melhor. Quanto maior for a destinação dos recursos das despesas de investimentos (transferências e aplicações diretas em material de consumo; serviços de terceiros; obras e instalações; equipamentos e material permanente; aquisição de imóveis; despesas de exercícios anteriores; indenizações e restituições etc.) para aplicar em obras e instalações, melhor será a incorporação de benfeitorias e instalações para atender a comunidade. Os conceitos sobre despesas com obras e instalações e despesas com investimentos constam na Portaria Conjunta STN/SOF n ${ }^{\text {3 }}$, de 15 de outubro de 2008 (BRASIL, 2008).

Os dados sobre o indicador de comprometimento dos recursos de despesas de investimentos em obras e instalações foram extraídos do sítio eletrônico da Secretaria do Tesouro Nacional - STN (BRASIL, 2016) e refletem a situação dos recursos dos Estados e do Distrito Federal no dia 31 de dezembro dos anos de 2013, 2014 e 2015 (aspecto temporal da avaliação). No ano de 2012 não foram disponibilizados os dados dos Estados do Rio de Janeiro e Roraima e ainda, no ano de 2010, o Estado de Roraima também não disponibilizou seus dados. Assim, não foi possível utilizar uma série histórica dos exercícios financeiros de 2010 a 2015.

Para avaliar o desempenho dos programas do governo, os resultados das ações de governo de forma agregada ou individual são necessários estabelecer os critérios (COSTA; CASTANHAR, 2003; SECCHI, 2013).

Nesta investigação, o critério estabelecido nas avaliações de desempenhos da alocação de recursos de investimentos em obras e instalações (2013 a 2015) é o da eficiência alocativa (ROSENBLATT; SHIDLO, 1996; REZENDE, 1995; REZENDE, 1997; BUGARIN, 2001; CATALÁN; BALLVE, 2009).

Os recursos alocados por um governo traduzem o tipo e a natureza do padrão de preferências alocativas de tal governo (REZENDE, 1997). Os eleitores devem comparar as ofertas de serviços públicos de seus governos com os de outras regiões 
(ROSENBLATT; SHIDLO; 1996). As preferências alocativas se referem a divisão dos recursos financeiros públicos como sendo o fim último da ação do governo. Eficiência alocativa, para Bugarin (2001), trata a questão de como distribuir os recursos e a própria produção.

A eficiência alocativa mostra a capacidade de uma unidade escolher um conjunto de insumos (CATALÁN; BALLVE, 2009). A eficiência na utilização dos recursos públicos requer um controle permanente da sociedade sobre o estado (REZENDE, 1995). O gasto realizado em um conjunto fixo de políticas públicas expressa com relativa precisão as preferências alocativas (REZENDE, 1997).

Neste contexto, esta pesquisa avalia a eficiência da alocação dos recursos financeiros (inputs) para atender às comunidades de forma agregada em obras e instalações, a partir de uma visão macro de desempenho entre os gestores públicos. $\mathrm{O}$ desempenho é apurado pelo resultado da ponderação dos coeficientes e as variâncias das variáveis definidas em relação aos escores padronizados, a partir de equações lineares. O efeito prático da avaliação é que o melhor desempenho traduz a melhor eficiência alocativa.

\subsection{Mensuração quantitativa e modelo teórico e empírico}

A métrica quantitativa utilizada para elaborar o índice de desempenho é a Análise de Componentes Principais (ACP). Sua utilização está amparada na Teoria da Medição (STEVENSON, 1981; MARTINS, 2005; ARIAS, 2010; COHEN; FRANCO, 2012).

Para Arias (2010), a Teoria da Representação da Medição ou simplesmente Teoria da Medição, a medição, no sentido mais amplo, é a atribuição de números a objetos ou eventos, de acordo com as regras. $\mathrm{O}$ autor esclarece ainda, que a estatística é uma ciência útil para a pesquisa empírica, seja em psicologia ou qualquer outra ciência. É geralmente conhecida como a ciência dos grandes números, porque suas leis e princípios atingem o seu prazo de validade máximo em grandes conjuntos de casos ou eventos.

Martins (2005) esclarece que a estatística não cria leis ou teorias, seu grande valor está em fornecer subsídios para que o pesquisador utilize as informações relevantes, visando à construção ou verificação de teorias. Para Stevenson (1981), há 
dois objetivos válidos e razoáveis para o estudo da estatística: desenvolver a habilidade na resolução de problemas e discernir entre problemas a que a estatística pode aplicar-se e problemas a que ela não se aplica.

Pela Teoria da Medição, de acordo com Cohen e Franco (2012), os números são símbolos com dois significados: o quantitativo habitual, que implica que com eles podem ser realizadas operações algébricas, e o qualitativo, que pode significar uma denominação arbitrária ou estabelecer uma ordem.

Convém ressalvar que a utilização da Teoria da Medição nos procedimentos metodológicos tem a finalidade de ratificar a importância da utilização de métricas quantitativas na elaboração de instrumentos de avaliação de desempenho nas pesquisas de resultados de gestões públicas.

O modelo teórico para atender o objetivo, a partir da utilização da Análise de Componentes Principais (ACP), está amparado nos ensinamentos de Mingoti e Silva (1997), Kubrusly (2001), Jolliffe (2002), Timm (2002), Vyas e Kumaranayake (2006), Mingoti (2007), Johnson e Wichern (2007), Manly (2008), Field (2009), Lattin, Carroll e Green (2011), Ribas e Vieira (2011), Ayres (2012) e Silva, Silva e Borges (2015).

As variáveis observadas são decompostas em seus autovalores (variâncias) e autovetores (coeficientes padronizados) em equações de combinações lineares pela técnica da Análise de Componentes Principais (ACP). Todas as variáveis observadas são incluídas nas equações dos escores de desempenho dos componentes principais (SILVA; SILVA; BORGES, 2015).

A ACP pode ser usada para construir um índice com a combinação linear das variáveis que tenha a maior variância possível. Os índices ou componentes não são correlacionados, sendo que cada componente é uma combinação linear ponderada das variáveis iniciais. O primeiro componente é um índice de desempenho global e em termos de ordenação, pode esperar que os primeiros componentes principais sejam suficientes para descreverem as diferenças entre os objetos (KUBRUSLY, 2001; VYAS; KUMARANAYAKE, 2006; MINGOTI, 2007; MANLY, 2008).

Timm (2002) argumenta que os componentes principais são usados para descobrir e interpretar as dependências que existem entre as variáveis, e para examinar as relações que possam existir entre os indivíduos. 
Para utilizar a ACP é necessário que haja correlação entre as variáveis (MINGOTI, 2007; FIELD, 2009; LATTIN; CARROLL; GREEN, 2011), que a matriz de correlação não pode ser identidade (FIELD, 2009). Deve haver, também normalidade multivariada (MINGOTI, 2007) e o determinante da matriz de correlação deve ser maior que 0.00001 (FIELD, 2009).

O desenvolvimento dos componentes principais não requer uma aceitação normal multivariada e sim da matriz de correlação ou da matriz de covariância (JOHNSON; WICHERN, 2007). As variáveis observadas não dependem de qualquer suposição sobre distribuição de probabilidade (MINGOTI; SILVA, 1997). Não há pressuposições em relação às variáveis originais (AYRES, 2012) e ainda, as variáveis podem ser contínuas e distribuídas normalmente ou não (JOLLIFFE, 2002).

Neste contexto, a Tabela 1 apresenta os dados necessários para validar a utilização da Análise de Componentes Principais (ACP).

Tabela 1 - Validação da utilização da Análise de Componentes Principais (ACP)

\begin{tabular}{cccc}
\hline \multicolumn{4}{c}{ Matriz de Correlação } \\
\hline Anos & 2013 & 2014 & 2015 \\
\hline 2013 & 1 & - & - \\
2014 & 0.8092 & 1 & - \\
2015 & 0.5588 & 0.5083 & 0.234 \\
\hline \multicolumn{4}{c}{ Teste de Esfericidade de Bartlett - Qui-quadrado aproximado } \\
\hline Calculado & & 35.074 \\
Graus de liberdade & & 3 \\
Significância & & 0.000 \\
Valor crítico (tabela de distribuição) & & 7.8147 \\
\hline
\end{tabular}

Fonte: dados da pesquisa.

Observa-se na Tabela 1, que os pressupostos para utilizar a ACP, nesta pesquisa foram cumpridos: existência de correlação; o determinante da matriz de correlação é maior que o exigido e há normalidade multivariada (o qui-quadrado calculado é maior que o valor crítico no Teste de Esfericidade de Bartlett).

Para operacionalizar o cálculo dos índices de desempenho com a ACP, o Quadro 3 sintetiza o modelo empírico utilizado, a partir das contribuições da literatura citada para o modelo teórico.

Quadro 3 - Modelo empírico do cálculo do índice de desempenho realizado pela Análise de Componentes Principais (ACP)

\begin{tabular}{|l|}
\hline$Y_{n}=\sum A_{n} Z_{n}$ (equações lineares) \\
\hline$Y_{n}=$ escores dos componentes principais dos autovalores $>1$ [somatório dos autovetores normalizados \\
\hline
\end{tabular}




\begin{tabular}{|l|}
\hline multiplicados pelas variáveis padronizadas] \\
\hline$\sum=$ somatório \\
\hline $\mathrm{A}_{\mathrm{n}}=$ autovetores normalizados (coeficientes de autovetores de $\mathrm{X}_{\mathrm{n}}$ ) - ponderações das variáveis \\
\hline $\begin{array}{l}\mathrm{Z}_{\mathrm{n}}=\text { variáveis padronizadas }(\mathrm{X}-\bar{X}) / \text { desvio-padrão de } \mathrm{X} \text { [variáveis menos a média das variáveis divididas } \\
\text { pelo desvio-padrão das variáveis] }\end{array}$ \\
\hline $\begin{array}{l}\text { IGD }=\sum \mathrm{Y}_{\mathrm{n}} \chi_{\mathrm{n}} / \sum \chi_{\mathrm{n}} \text { [somatório dos escores dos componentes principais dos autovalores }>1 \text { multiplicados } \\
\text { pelos autovalores de cada componente dividido pelo somatório dos autovalores] }\end{array}$ \\
\hline $\begin{array}{l}\text { IGD }=\text { Índice Geral de Desempenho }- \text { ordenação [ranking de desempenho com base nos escores dos } \\
\text { componentes principais dos autovalores }>1 \text { ] }\end{array}$ \\
\hline$\chi_{\mathrm{n}}=$ autovalores $>1$ [ponderação do Índice Geral de Desempenho] \\
\hline Interpolação dos resultados na faixa de 100 a 0. \\
\hline Divisão dos resultados por 100. \\
\hline IDROI = Índice de Desempenho de Alocação de Recursos em Obras e Instalações [faixa de 1 a 0]. \\
\hline
\end{tabular}

Fonte: elaborado pelos autores.

Os escores de desempenhos são calculados na $\mathrm{ACP}$, a partir dos autovalores (variância) e autovetores (coeficientes das variáveis). Os autovalores representam o poder explicativo do componente em relação à variância das variáveis originais (observadas) e são medidos em unidades de variância (MANLY, 2008; AYRES, 2012). $\mathrm{Na}$ análise dos componentes principais é recomendável obter as variâncias de porcentagem alta, ou seja, acima de $80 \%$ ou mais (MANLY, 2008). A soma dos autovalores é igual a $p$ e representam o número de variáveis $\mathrm{X}$ escolhidas.

Os autovetores são os coeficientes das variáveis $\mathrm{X}$ padronizadas usados para calcular escores dos componentes principais. Os autovetores representam o módulo unitário associado a cada autovalor e as direções dos eixos dos componentes principais (MANLY, 2008; AYRES, 2012).

Os escores de desempenhos podem ser calculados em todas as equações dos componentes principais, mas os escores do componente 1 representam a maior variância. De acordo com Ribas e Vieira (2011), cada componente é uma função linear das variáveis originais, sendo essa função similar à regressão múltipla, exceto pelo fato de que não há intercepto.

Os escores de desempenhos calculados pela ACP (Quadro 3) apresentam valores positivos e negativos e são utilizados para ordenar (ranquear) os resultados. As primeiras posições representam os melhores desempenhos (mais eficientes) e nesta investigação são denominados de IGD (Índice Geral de Desempenho). Para apresentar 
os resultados somente em valores positivos, foi utilizada a interpolação, considerando o maior valor dos escores como 100 e o menor como zero (normalização de dados) e depois todos os valores foram divididos por 100 (faixa de 1 a 0 ). O índice de desempenho (somente valores positivos) foi denominado de IDROI - Índice de Desempenho de Alocação de Recursos em Obras e Instalações.

A Tabela 2 apresenta as equações lineares e os autovalores utilizados para elaborar o Índice de Desempenho de Alocação de Recursos em Obras e Instalações (IDROI).

Tabela 2 - Equações lineares e autovalores

\begin{tabular}{lccc}
\hline \multicolumn{4}{c}{ Equações lineares (autovetores e escores padronizados) } \\
\hline $\mathrm{Y}_{1}=$ & $0.6129 *\left(\mathrm{Z} \_2013\right)$ & $+0.6004 *\left(\mathrm{Z} \_2014\right)$ & $+0.5136 *\left(\mathrm{Z} \_2015\right)$ \\
$\mathrm{Y}_{2}=$ & $-0.3025^{*}\left(\mathrm{Z} \_2013\right)$ & $-0.4222^{*}\left(\mathrm{Z} \_2014\right)$ & $+0.8545^{*}\left(\mathrm{Z} \_2015\right)$ \\
$\mathrm{Y}_{3}=$ & $-0.7299^{*}\left(\mathrm{Z} \_2013\right)$ & $+0.6791 *\left(\mathrm{Z} \_2014\right)$ & $+0.0772 *\left(\mathrm{Z} \_2015\right)$ \\
\hline \multicolumn{5}{c}{ Autovalores (variância) } \\
\hline $\mathrm{CP}$ & 1 & 2 & 3 \\
\hline Variância $(\%)$ & 2.2609 & 0.5511 & 0.1880 \\
\hline Legenda: $\mathrm{Y}_{\mathrm{n}}=$ equações & $75.36 \%$ & $18.37 \%$ & $6.27 \%$ \\
componentes principais. & &
\end{tabular}

O Índice de Desempenho de Alocação de Recursos em Obras e Instalações (IDROI) foi elaborado com as equações lineares $\mathrm{Y}_{1}$ e $\mathrm{Y}_{2}$ para obter uma variância superior a 80\%, conforme recomendação de Manly (2008). As equações foram ponderadas pelos autovalores dos componentes 1 e 2 .

A variância dos componentes 1 e 2 (equações lineares $\mathrm{Y}_{1}$ e $\mathrm{Y}_{2}$ ) foi de $93.73 \%$ $(2.2609 / 3 * 100 \%+0.5511 / 3 * 100 \%)$. A variância total é igual a 3, que corresponde a 3 variáveis (indicador de comprometimento dos recursos de despesas de investimentos em obras e instalações dos anos de 2013, 2014 e 2015).

Os cálculos foram realizados com os softwares BioEstat 5.0® (AYRES et al., 2007) e SPSS Statistic 21®. O software BioEstat 5.0® apresenta os resultados dos cálculos dos escores dos componentes principais e o SPSS Statistic $21{ }^{\circledR}$, o determinante da matriz de correlação e o qui-quadrado do Teste de Esfericidade de Bartlett.

Convém ressalvar que os esclarecimentos detalhados sobre a utilização da Análise de Componentes Principais (ACP), nesta investigação, visam enfatizar a elaboração de índices de desempenho com essa técnica. Desse modo, os procedimentos constituem 
contribuições para a literatura para que outros pesquisadores utilizem tanto no setor público como no setor privado.

\section{RESULTADOS E ANÁLISES}

A Tabela 3 apresenta os indicadores de comprometimento dos recursos de despesas de investimentos em obras e instalações dos anos de 2013, 2014 e 2015 dos Estados e do Distrito Federal. Os Estados e o Distrito Federal estão posicionados em ordem alfabética.

Tabela 3 - Indicador de comprometimento dos recursos de despesas de investimentos em obras e instalações

\begin{tabular}{lrrr|lrrr}
\hline Estados e o DF / anos & $\mathbf{2 0 1 3}$ & $\mathbf{2 0 1 4}$ & $\mathbf{2 0 1 5}$ & Estados e o DF / anos & $\mathbf{2 0 1 3}$ & $\mathbf{2 0 1 4}$ & $\mathbf{2 0 1 5}$ \\
\hline Acre & 0.3910 & 0.3570 & 0.5755 & Pará & 0.7138 & 0.5807 & 0.3705 \\
Alagoas & 0.8284 & 0.8537 & 0.7832 & Paraíba & 0.7842 & 0.7346 & 0.8253 \\
Amapá & 0.7301 & 0.7140 & 0.6106 & Paraná & 0.1882 & 0.1783 & 0.1869 \\
Amazonas & 0.6073 & 0.5760 & 0.5293 & Pernambuco & 0.5110 & 0.4675 & 0.4054 \\
Bahia & 0.5391 & 0.4771 & 0.4268 & Piauí & 0.6252 & 0.7111 & 0.4129 \\
Ceará & 0.4930 & 0.5523 & 0.6197 & Rio de Janeiro & 0.7631 & 0.7451 & 0.5681 \\
Distrito Federal & 0.8908 & 0.7123 & 0.6444 & Rio Grande do Norte & 0.7215 & 0.4744 & 0.6436 \\
Espírito Santo & 0.6872 & 0.5757 & 0.7014 & Rio Grande do Sul & 0.2884 & 0.3541 & 0.4357 \\
Goiás & 0.8182 & 0.7997 & 0.4861 & Rondônia & 0.5151 & 0.3935 & 0.3353 \\
Maranhão & 0.6808 & 0.6721 & 0.7959 & Roraima & 0.4856 & 0.7081 & 0.5592 \\
Mato Grosso & 0.8335 & 0.8271 & 0.6516 & Santa Catarina & 0.5213 & 0.4487 & 0.5744 \\
Mato Grosso do Sul & 0.7217 & 0.8338 & 0.5833 & São Paulo & 0.6253 & 0.6323 & 0.5941 \\
Minas Gerais & 0.4647 & 0.5215 & 0.2955 & Sergipe & 0.4311 & 0.5520 & 0.7099 \\
& & & & Tocantins & 0.5763 & 0.7902 & 0.3995 \\
\hline
\end{tabular}

Fonte: dados da pesquisa.

Observa-se na Tabela 3 que o maior resultado (melhor aplicação de recursos) do ano de 2013 foi obtido pelo Distrito Federal (0.8908); em 2014 pelo Estado de Alagoas (0.8537) e em 2015 pelo Estado do Paraíba (0.8253).

O pior resultado (a menor aplicação de recursos de investimentos em obras e instalações) de todos os anos avaliados foi obtido pelo Estado do Paraná: 2013 (0.1882); 2014 (0.1783) e 2015 (0.1869). Isto significa que o Estado do Paraná aplicou menos recursos de despesas de investimentos em obras e instalações para atender a comunidade na avaliação comparativa de desempenho.

A média de aplicação dos recursos por todos os Estados e o Distrito Federal foi diminuída no período avaliado (anos de 2013 a 2015). No ano de 2013, a média foi de 0.6087 (maior aplicação); em 2014 de 0.6015 e em 2015 de 0.5453. Pode-se observar na 
Tabela 3, que os Estados: Amapá; Amazonas; Bahia; Goiás; Mato Grosso; Pará; Pernambuco; Rio de Janeiro; Rondônia e o Distrito Federal diminuíram os recursos aplicados em obras e instalações nos anos de 2014 e 2015.

Chama atenção os resultados do Estado do Rio Grande do Sul no período avaliado. No ano de 2013, para cada $\mathrm{R} \$ 1,00$ de recursos de despesas de investimentos, somente $R$ \$ 0,28 foram destinados para obras e instalações. O restante $(R \$ 0,72)$ foi destinado para outras aplicações (transferências; aquisição de material de consumo; prestação de serviços de terceiros; aquisições de equipamentos e material permanente etc.).

O Estado de Minas Gerais diminuiu a aplicação de recursos em obras e instalações no ano de 2015 em relação a 2013 e 2014. Estes achados são ratificados pela notícia veiculada no Diário do Comércio (2015): a crise financeira impacta Minas Gerais e o governo do Estado perde a capacidade de investimento e terá de cortar verbas para obras.

Quanto aos gastos em períodos de eleição, observa-se na Tabela 3, que os Estados de Alagoas, Mato Grosso do Sul, Piauí, Roraima e Tocantins aumentaram os gastos por ocasião das eleições ocorridas no ano de 2014 (maior quociente do indicador de obras e instalações com despesas de investimentos) em relação ao ano de 2013 e diminuíram as aplicações no ano pós-eleição (2015). Tal comportamento sob a ótica da Teoria da Escolha Pública (PEREIRA, 1997; AIDT; VEIGA; VEIGA, 2011) pode ser denominado de oportunista. Neste caso, não é necessário analisar o Plano Plurianual, a Lei Orçamentária Anual, as ideologias partidárias, os problemas, a agenda etc. Os resultados evidenciados nas demonstrações públicas sintetizam essas vertentes e a teoria pode ser comprovada ou não.

A Tabela 4 apresenta os escores de desempenhos (equações $\mathrm{Y}_{1}$ e $\mathrm{Y}_{2}$ ) calculados com base nos esclarecimentos constantes do Quadro 3. O Índice Geral de Desempenho (IGD) apresenta valores negativos e positivos e o Índice de Desempenho de Alocação de Recursos em Obras e Instalações (IDROI) apresenta apenas valores positivos, na faixa de 1 (melhor desempenho - mais eficiente) a 0 (pior desempenho - menos eficiente). 
Tabela 4 - Ranking de desempenho de alocação de recursos em obras e instalações (2013-2015) - Índice de Desempenho de Alocação de Recursos com Obras e Instalações

\begin{tabular}{clccc}
\hline Posição & \multicolumn{1}{c}{ Estados } & IGD & Interpolação & IDROI \\
\hline $1^{\mathbf{o}}$ & Alagoas & 2.0111 & 100 & 1 \\
$2^{\mathbf{o}}$ & Paraíba & 1.7773 & 95.64 & 0.9564 \\
$3^{\mathrm{o}}$ & Mato Grosso & 1.4787 & 90.08 & 0.9008 \\
$4^{\mathbf{o}}$ & Distrito Federal & 1.3280 & 87.27 & 0.8727 \\
$5^{\circ}$ & Maranhão & 1.2647 & 86.09 & 0.8609 \\
$6^{\circ}$ & Mato Grosso do Sul & 0.9636 & 80.48 & 0.8048 \\
$7^{\mathbf{o}}$ & Amapá & 0.8055 & 77.54 & 0.7754 \\
$8^{\circ}$ & Rio de Janeiro & 0.8046 & 77.52 & 0.7752 \\
$9^{\circ}$ & Goiás & 0.7688 & 76.85 & 0.7685 \\
$10^{\circ}$ & Espírito Santo & 0.7091 & 75.74 & 0.7574 \\
$11^{\circ}$ & Rio Grande do Norte & 0.3466 & 68.99 & 0.6899 \\
$12^{\circ}$ & São Paulo & 0.2921 & 67.97 & 0.6797 \\
$13^{\circ}$ & Sergipe & 0.0438 & 63.34 & 0.6334 \\
$14^{\circ}$ & Roraima & -0.0091 & 62.36 & 0.6236 \\
$15^{\circ}$ & Amazonas & -0.1221 & 60.25 & 0.6025 \\
$16^{\circ}$ & Ceará & -0.1317 & 60.07 & 0.6007 \\
$17^{\circ}$ & Tocantins & -0.1769 & 59.23 & 0.5923 \\
$18^{\circ}$ & Piauí & -0.1897 & 58.99 & 0.5899 \\
$19^{\circ}$ & Pará & -0.4276 & 54.56 & 0.5456 \\
$20^{\circ}$ & Santa Catarina & -0.4687 & 53.79 & 0.5379 \\
$21^{\circ}$ & Bahia & -0.8998 & 45.76 & 0.4576 \\
$22^{\circ}$ & Acre & -1.0046 & 43.81 & 0.4381 \\
$23^{\circ}$ & Pernambuco & -1.0711 & 42.57 & 0.4257 \\
$24^{\circ}$ & Minas Gerais & -1.4647 & 35.24 & 0.3524 \\
$25^{\circ}$ & Rondônia & -1.4908 & 34.75 & 0.3475 \\
$26^{\circ}$ & Rio Grande do Sul & -1.7816 & 29.33 & 0.2933 \\
$27^{\circ}$ & Paraná & -3.3558 & 0 & 0 \\
\hline
\end{tabular}

Legenda: IGD = Índice Geral de Desempenho; IDROI = Índice de Desempenho de Alocação de Recursos com Obras e Instalações.

Fonte: dados da pesquisa.

O Índice de Desempenho de Alocação de Recursos com Obras e Instalações (IDROI) indica como foram aplicados os recursos pelas entidades de forma comparativa e não representa um conjunto de dados isolados. A criação do ranking de desempenho é uma consequência para verificar essas aplicações (análise comparativa).

Ao delimitar as variáveis que compõem o índice desempenho, outras podem ficar de fora da avaliação, mas tal procedimento é natural, haja vista que avaliar todas as variáveis que expressam qualidade dos gastos públicos em artigos científicos não é possível pela quantidade de páginas que podem ser expressas. Convém ressalvar ainda, que em teses e dissertações também existem delimitações. Como argumenta Silva, Silva e Silva (2016), infelizmente ou felizmente (inviabilidade) não é possível realizar avaliações do todo (universo). As avaliações são realizadas com aproximações (proxies) do universo. 
Observa-se na Tabela 4, que no ranking de desempenho, os Estados de Alagoas, Paraíba e Mato Grosso ficaram nas primeiras posições (mais eficientes) e os Estados de Rondônia, Rio Grande do Sul e Paraná ficaram nas últimas posições (menos eficientes).

Pelos resultados apresentados na Tabela 3 e ratificado na notícia veiculada no Jornal NH (2016) sobre a crise financeira mais grave do país, o Rio Grande do Sul ficou na penúltima posição. Já o Estado do Rio de Janeiro, apesar do Governo ter decretado estado de calamidade pública devido à crise por temer total colapso em saúde, segurança, educação e mobilidade (G1.GLOBO.COM, 2016), ficou na $8^{\mathrm{a}}$ posição do ranking de desempenho (avaliação comparativa). Esses resultados mostram o desempenho avaliado de forma comparativa com base nos dados que foram relativizados pelo indicador de comprometimento dos recursos de despesas de investimentos em obras e instalações.

A maioria dos Estados e o Distrito Federal (14) apresentou valores de escores negativos (IGD). Isto mostra uma tendência de se posicionarem abaixo da percentagem média geral de cada estado e no caso dos escores positivos (13) de se posicionaram acima. Observa-se assim, que mais de 52\% dos Estados e o Distrito Federal ficaram abaixo da média geral do índice de desempenho de alocação de recursos com obras e instalações.

As avaliações realizadas com base em análise descritiva (Tabela 3) podem e devem ser realizadas pelas Controladorias Públicas e pelos Tribunais de Contas dos Estados e do Distrito Federal. A utilização de métrica quantitativa (Tabela 4) requer conhecimentos de estatística e são utilizadas em pesquisas avaliativas como contribuições acadêmicas.

Observa-se também com base nos resultados evidenciados na Tabela 3 e na Tabela 4, a relevância de avaliar os resultados da gestão pública com base em indicadores (ZUCATTO et al., 2009): indicação de problemas.

Neste prisma, com base na Teoria dos Stakeholders (GOMES, 2006; FREEMAN et al., 2010; HARRISON; ROUSE; DE VILLIERS, 2012; CONNOLLY; HYNDMAN, 2013), como principais Stakeholders no processo de avaliação de resultados da gestão pública por indicador (Tabela 3) e índice de desempenho (objetivo desta investigação - Tabela 4), destacam os cidadãos, os governos estaduais e distrital 
(gestores públicos) e os órgãos de fiscalização (Controladorias, Tribunais de Contas dos Estados e do Distrito Federal).

As implicações decorrentes da avaliação mostram deficiências na alocação de recursos em obras e instalações dos Estados e do Distrito Federal (gestores públicos) e na falta de fiscalização dos órgãos competentes (Controladorias e Tribunais de Contas). Desse modo, os cidadãos podem ser prejudicados com os serviços públicos de obras e instalações. Pode-se afirmar que os órgãos de controle devem colocar em suas rotinas, as análises de indicadores para detectarem problemas. Neste sentido, Amaral (2003) contextualiza teorias e aplicações práticas na utilização de indicadores gerais, sociais e específicos para analisar resultados no setor público.

O Índice de Desempenho de Alocação de Recursos com Obras e Instalações (IDROI) e o indicador de comprometimento dos recursos de despesas de investimentos em obras e instalações constituem contribuições desta investigação para a literatura de avaliação de resultados de gestões públicas. Desse modo, não existem comparações quantos aos achados. Podem ser feitas comparações isoladas como as realizadas com as reportagens jornalísticas.

\section{CONSIDERAÇÕES FINAIS}

Este artigo, em atenção ao objetivo formulado, elaborou o Índice de Desempenho de Alocação de Recursos com Obras e Instalações (IDROI). O IDROI foi elaborado com base no indicador do comprometimento dos recursos de despesas com investimento em obras e instalações. O indicador visa identificar o quanto dos recursos orçamentários das despesas de capital do elemento de despesa denominado de investimentos foi destinado para atender diretamente as obras e instalações em proveito da comunidade. Desse modo, questões subjacentes com a alocação de recursos: superfaturamento de materiais e obras, desvios de recursos e fraudes em licitações etc. não são avaliados. O IDROI avalia a eficiência alocativa dos gestores públicos ao administrarem os recursos das despesas de investimentos que foram destinados para obras e instalações.

A avaliação de desempenho calculada com o IDROI não evidencia que maior gasto na alocação de recursos resulte em melhor desempenho. A Análise de Componentes Principais calcula índices com base em equações lineares em que os 
escores dos componentes principais normalizados (autovalores) são multiplicados pelas variáveis padronizadas (recursos aplicados menos a sua média divididos pelo desviopadrão). Assim, o desempenho é comparativo entre os todos órgãos avaliados e o índice elaborado representa mais um instrumento de avaliação de desempenho de gestores públicos.

A qualidade e a eficiência do gasto público envolvem muitos fatores do universo das políticas públicas (variáveis partidárias; institucionais; análises de custo-benefício; custo-eficiência e risco; problema; alternativas; dados; limites constitucionais e discricionários; atuação de lobbies; grau de investimento local etc.) e se o avaliador não delimitar o seu campo de análise não poderá fazer inferências.

As Teorias da Escolha Pública e dos Stakeholders podem ser aplicadas para fazer as inferências sobre os gastos públicos. Uma das contribuições da Teoria da Escolha Pública ao aplicar o método da ciência econômica no âmbito da ciência política se refere ao comportamento oportunista dos gastos dos governos por ocasião das eleições (antes, durante e depois). Neste sentido, as aplicações de recursos realizadas pelos Estados de Alagoas, Mato Grosso do Sul, Piauí, Roraima e Tocantins no ano eleitoral de 2014 sugerem tal oportunismo (maior quociente do indicador de obras e instalações com despesas de investimentos em relação ao ano de 2013 e diminuição das aplicações no ano pós-eleição).

A identificação dos principais stakeholders (partes interessadas) no processo de avaliação de resultados da gestão pública por indicador pode ser realizada com a Teoria dos Stakeholders. Nesta pesquisa destacam os cidadãos, os governos estaduais e distrital (gestores públicos) e os órgãos de fiscalização (Controladorias, Tribunais de Contas dos Estados e do Distrito Federal). A não alocação de recursos prejudica os cidadãos e competem aos órgãos de fiscalização observarem que os gestores públicos cumpram com suas obrigações.

Como contribuições desta pesquisa, destacam o conceito do indicador do comprometimento dos recursos de despesas com investimento em obras e instalações e os procedimentos metodológicos para a elaboração de um instrumento de avaliação de desempenho com base em métrica quantitativa (Índice de Desempenho de Alocação de Recursos com Obras e Instalações - IDROI). 
Convém ressalvar que poderiam ser incluídas mais variáveis (indicadores do comprometimento dos recursos de despesas com investimentos em obras e instalações) na avaliação (execução orçamentária de outros anos), mas os dados não estão disponíveis nos sítios eletrônicos de alguns Estados e do Distrito Federal para comporem uma série histórica maior (2009, 2010, 2011 etc.). Contudo, espera-se que os resultados desta investigação motivem outros pesquisadores a realizarem mais pesquisas de avaliação de resultados (trabalhos futuros) de forma descritiva ou com a utilização da métrica quantitativa (Análise de Componentes Principais - ACP). Recomenda-se pesquisas correlatas na avaliação de desempenho na alocação de recursos de obras e instalações em municípios.

Convém ressalvar também, que ao utilizar informações de reportagens jornalísticas sobre gastos públicos, esta pesquisa convalida a importância da utilização das ciências para tentar resolver problemas da sociedade. O conhecimento científico deve ser utilizado para análises de fatos reais e as reportagens mostram esses fatos. As avaliações acadêmicas servem para prestarem suas contribuições nas avaliações de fatos reais. Desse modo, os artigos científicos poderão ser lidos e entendidos pelos cidadãos.

Compreendidos os parâmetros subjacentes a esta pesquisa, foi possível responder o problema de pesquisa e assim concluir com base no ranking do Índice de Desempenho de Alocação de Recursos com Obras e Instalações (IDROI), que os Estados de Alagoas, Paraíba e Mato Grosso ficaram nas primeiras posições (foram mais eficientes) e os Estados de Rondônia, Rio Grande do Sul e Paraná ficaram nas últimas posições (menos eficientes).

Verifica-se também, que as avaliações realizadas com base em análise descritiva podem e devem ser realizadas pelas Controladorias Públicas e pelos Tribunais de Contas dos Estados e do Distrito Federal (stakeholders). A utilização de métrica quantitativa requer conhecimentos de estatística e são utilizadas em pesquisas avaliativas como contribuições acadêmicas.

\section{REFERÊNCIAS}

ABBOTT, A.; JONES, P. Procyclical government spending: a public choice analysis. Public Choice (2013) 154:243-258. DOI 10.1007/s11127-011-9816-9. 
AIDT, T. S.; VEIGA, F. J.; VEIGA, L. G. Election results and opportunistic policies: A new test of the rational political business cycle model. Public Choice (2011) 148: 2144. DOI 10.1007/s11127-010-9644-3.

AMARAL, R. M. A avaliação de resultados no setor público: teoria e aplicação prática no Estado do Rio de Janeiro. Rio de Janeiro: Tribunal de Contas do Estado do Rio de Janeiro, 2003.

ANDRADE, N. A. Contabilidade pública na gestão municipal. 3. ed. São Paulo: Atlas, 2007.

ARIAS, E. R. Estadística: Medición, Descripción e Inferencia. Perspectivas Psicológicas, Santo Domingo (Rep. Dom.), Volúmenes 6 y 7. Año X. 2010, Edición Especial.

AYRES, M. Elementos de bioestatística: a seiva do açaizeiro. 2. ed. Belém: Supercores, 2012.

AYRES JÚNIOR, M.; AYRES, D. L.; SANTOS, A. A. S.; AYRES, L. L. BioEstat 5.0 - Aplicações estatísticas nas áreas das ciências biomédicas. Belém, PA: Sociedade Civil Mamirauá, 2007. PA.

BORTOLUZZI, S. C.; ENSSLIN, S. R.; LYRIO, M. V. L.; ENSSLIN, L. Avaliação de desempenho econômico-financeiro: uma proposta de integração de indicadores contábeis tradicionais por meio da metodologia multicritério de apoio à decisão construtivista (MCDA-C). Revista Alcance - Eletrônica, Vol. 18 - n. 2 - p. 200-218 / abr-jun 2011.

BRASIL. Lei $\mathrm{n}^{\circ}$ 4.320, de 17 de março de 1964. Estatui normas gerais de direito financeiro para elaboração e controle dos orçamentos e balanços da União, Estados, Municípios e do Distrito Federal. Diário Oficial [da] República Federativa do Brasil, Brasília-DF, 23 de março de 1964.

Lei Complementar $n^{\circ} 101$, de 04 de maio de 2000a (Lei de Responsabilidade Fiscal - LRF). Estabelece normas de finanças públicas voltadas para a responsabilidade na gestão fiscal e dá outras providências. Diário Oficial [da] República Federativa do Brasil, Brasília-DF, 05 de maio de 2000.

Tribunal de Contas da União. Técnicas de Auditoria: indicadores de desempenho e mapa de produtos. Boletim do Tribunal de Contas da União. Brasília-DF: TCU, Coordenadoria de Fiscalização e Controle, 2000b, 32p.

Ministério da Fazenda. Secretaria do Tesouro Nacional (STN) - Ministério do Planejamento, Orçamento e Gestão - Secretaria de Orçamento Federal (SOF). Portaria Conjunta $n^{\circ}$ STN/SOF $n^{\circ} 3$, de 15 de outubro de 2008. Aprova os Manuais de Receita Nacional e de Despesa Nacional e dá outras providências. Diário Oficial [da] República Federativa do Brasil, Brasília-DF, 16 de outubro de 2008. 
Ministério do Planejamento, Orçamento e Gestão (MPOG). Secretaria de Gestão. Melhoria da gestão pública por meio da definição de um guia referencial para medição do desempenho da gestão, e controle para o gerenciamento dos indicadores de eficiência, eficácia e de resultados do programa nacional de gestão pública e desburocratização. Produto 4: guia referencial para medição de desempenho e manual para construção de indicadores. Brasília-DF, dezembro de 2009.

$\begin{array}{llllll} & \text { Ministério da } & \text { Fazenda. Secretaria do Tesouro } & \text { Nacional (STN). Sobre } \\ \text { Prefeituras } & \text { e } & \text { Governos } & \text { Estaduais. } & \text { Disponível } & \text { em: }\end{array}$ $<$ https://www.tesouro.fazenda.gov.br/finbra-financas-municipais $>$. Acesso em: 10 ago. 2016.

BUGARIN, P. S. O princípio constitucional da eficiência: um enfoque doutrinário multidisciplinar. R. TCU, Brasília, v. 32, n. 87, jan/mar 2001.

CATALÁN, P. H.; BALLVE, P. F. Análisis de la eficiencia del gasto municipal y de sus determinantes. Economía, Vol. XXXII, N 63, semestre enero-junio 2009, pp. 113178.

COHEN, E.; FRANCO, R. Avaliação de projetos sociais. 10. ed. Petrópolis: Vozes, 2012.

CONNOLLY, C.; HYNDMAN, N. Towards charity accountability: narrowing the gap between provision and needs? Public Management Review, 15:7, 945-968, (2013). DOI: $10.1080 / 14719037.2012 .757349$.

COSTA, F. L.; CASTANHAR, J. C. Avaliação de programas públicos: desafios conceituais e metodológicos. RAP, Rio de Janeiro 37 (5): 969-92, Set./Out. 2003.

Diário do Comércio. Crise financeira impacta Minas. Governo do Estado perde a capacidade de investimento e terá de cortar verbas para obras. Belo Horizonte, 07 de abril de 2015. Disponível em:

<http://www.diariodocomercio.com.br/noticia.php?id=151967>. Acesso em 04 fev. 2016.

DINIZ, J. A; MACEDO, M. A. S.; CORRAR, L. J. Mensuração da eficiência financeira municipal no Brasil e sua relação com os gastos nas funções de governo. Gestão \& Regionalidade - Vol. 28 - No 83 - mai-ago/2012.

DRAIBE, S. M. Avaliação de implementação: esboço de uma metodologia de trabalho em políticas públicas. In: BARREIRA, M. C. R. N.; CARVALHO; M. C. B. (Org.). Tendências e perspectivas na avaliação de políticas e programas sociais. São Paulo: IEE/PUC-SP, 2001.

FIELD, A. Descobrindo a estatística usando o SPSS. Tradução de Lorí Viali. 2. ed. Porto Alegre: Artmed, 2009. 
FOUCAULT, M. 1; FRANÇOIS, A. La politique influence-t-elle les décisions publiques locales? Analyse empirique des budgets communaux de 1977 à 2001. In: Politiques et Management Public, vol. $23 \mathrm{n}^{\circ}$ 3, 2005. Le management public à l'épreuve de la politique. Actes du quatorzième Colloque international - Bordeaux, jeudi 17 mars et vendredi 18 mars 2005 organisé en collaboration avec Sciences-Po Bordeaux - Tome 1. pp. 79-100.

FOUCAULT, M.; MADIES, T.; PATY, S. Public spending interactions and local politics. Empirical evidence from French municipalities. Public Choice, (2008) 137: 57-80. DOI 10.1007/s11127-008-9312-z.

FRANCO-SANTOS, M.; LUCIANETTI, L.; BOURNE, M. Contemporary Performance Measurement Systems: a review of their consequences and a framework for research. Management Accounting Research, v. 23, n. 2, p. 79-119, 2012

FREEMAN, R. E.; HARRISON, J. S.; WICKS, A. C.; PARMAR, B.; COLLE, S. Stakeholder Theory: The State of the Art. Cambridge University Press, Cambridge, 2010 .

G1.Globo.com. Governo do RJ decreta estado de calamidade pública devido à crise - notícias em Rio de Janeiro. Rio de Janeiro, 17 de junho de 2016. Disponível em: $<$ http://g1.globo.com/rio-de-janeiro/noticia/2016/06/governo-do-rj-decreta-estado-de-ca lamidade-publica-devido-crise.htm>. Acesso em: 20 jul. 2017.

GOMES, R. C. Stakeholder Management in the Local Government Decision-Making Area: Evidences from a Triangulation Study with the English Local Government. RAC, Edição Especial 2006: 77-98.

HARRISON, J. A.; ROUSE, P.; DE VILLIERS, C. J. Accountability and Performance Measurement: A Stakeholder Perspective. JCC: The Business and Economics Research Journal, Volume 5, Issue 2, 2012, p. 243-258.

HELDEN, G. J. V.; JOHNSEN, A; VAKKURI, J. Distinctive research patterns on public sector performance measurement of public administration and accounting disciplines. Public Management Review, 10:5,641-65, 2008. DOI: 10.1080/14719030802264366.

JOHNSON, R. A.; WICHERN, D. W. Applied Multivariate Statistical Analysis. 6. ed. New Jersey: Prentice Hall, 2007.

JOLLIFFE, I.T. Principal component analysis. 2nd. edition. New York: SpringerVerlag, 2002.

Jornal NH. Rio Grande do Sul tem a crise financeira mais grave do País, afirma Sartori. Rio Grande do Sul, 26 de fevereiro de 2016. Disponível em: <http://www.jornalnh.com.br/_conteudo/2016/02/noticias/rio_grande_do_sul/283924-es tado-tem-a-crise-financeira-mais-grave-do-pais-afirma-sartori.html $>$. Acesso em: 20 jul. 2016. 
JUND, S. Administração, orçamento e contabilidade pública: teoria e 850 questões. 3. ed. Rio de Janeiro: Elsevier, 2008.

KUBRUSLY, L. S. Um procedimento para calcular índices a partir de uma base de dados multivariados. Pesquisa Operacional, Vol. 21, № 1, p. 107-117, junho de 2001.

LATTIN, J.; CARROLL, J. D.; GREEN, P. E. Análise de dados multivariados. Tradução de Harue Avritscher. São Paulo: Cengage Learning, 2011.

MANLY, B. J. F. Métodos estatísticos multivariados: uma introdução. Tradução de Sara Ianda Carmona. 3. ed. Porto Alegre: Bookman, 2008.

MARQUES, M. C. C. Tendências recentes de abordagem à contabilidade pública em Portugal. Revista Contabilidade \& Finanças - USP, São Paulo, n. 31, p. 96-108, janeiro/abril 2003.

MARTINS, G. A.; THEÓPHILO, C. R. Metodologia da investigação científica para ciências sociais aplicadas. 2. ed. São Paulo: Atlas, 2009.

MARTINS, G. A. Falando sobre teorias e modelos nas ciências contábeis. BBR Brazilian Business Review, Vol. 2, n 2, Vitória-ES, Brasil - Jul / Dez 2005, pp. 131144.

MATIAS-PEREIRA, J. Curso de administração pública: foco nas instituições e ações governamentais. 2. Ed. São Paulo: Atlas, 2009.

Curso de planejamento governamental: foco nas políticas públicas e nos indicadores sociais. São Paulo: Atlas, 2012a. $2012 b$.

Manual de metodologia da pesquisa Científica. 3. ed. São Paulo: Atlas,

Finanças Públicas: a política orçamentária no Brasil. 3. Ed. São Paulo: Atlas, 2006.

MCWILLIAMS, A.; SIEGEL, D. Corporate social responsibility: a theory of the firm perspective. The Academy of Management Review, 26(1), 117-127, 2001. DOI: 10.5465/AMR.2001.4011987.

MELLO, G. R.; SLOMSKI, V. A situação financeira dos estados brasileiros: uma proposta utilizando análise discriminante. RCO - Revista de Contabilidade e Organizações - FEARP/USP, v. 1, n. 1, p. 73 - 86 set./dez. 2007.

MINGOTI, S. A. Análise de dados através de métodos de estatística multivariada: uma abordagem aplicada. $1^{\mathrm{a}}$ reimpressão. Belo Horizonte: Editora UFMG, 2007. 
SILVA, A. F. Um exemplo de aplicação de técnicas de estatística multivariada na construção de índices de preços. Nova Economia, Belo Horizonte, v. 7, n. 2, 1997.

MUSGRAVE, R. A.; MUSGRAVE, P. B. Finanças públicas: teoria e prática. Tradução de Carlos Alberto Primo Braga. Rio de Janeiro: Campus, 1980.

PEREIRA, P. T. A teoria da escolha pública (public choice): uma abordagem neoliberal? Análise Social, vol. xxxii (141),1997 (2. $\left.{ }^{\circ}\right), 419-442$.

RAMOS, M. P.; SCHABBACH, L. M. O estado da arte da avaliação de políticas públicas: conceituação e exemplos de avaliação no Brasil. Rev. Adm. Pública - Rio de Janeiro 46(5):1271-294, set./out. 2012.

REZENDE, F. C. Descentralização, gastos públicos e preferências alocativas dos governos locais no Brasil (1980-1994). Dados, v. 40, n. 3, Rio de Janeiro,1997.

REZENDE, F. Federalismo fiscal no Brasil. Revista de Economia Política, vol. 15, n 3, julho-setembro/1995.

RIBAS, J. R.; VIEIRA, P. R. C. Análise multivariada com o uso do SPSS. Rio de Janeiro: Ciência Moderna, 2011.

ROSENBLATT, D.; SHIDLO, G. Quem tem mais recursos para governar? Uma comparação das receitas per capita dos estados e dos municípios brasileiros. Revista de Economia Aplicada, vol. 16, nº 1 (61), janeiro-março/1996.

SECCHI, L. Políticas públicas: conceitos, esquemas de análise, casos práticos. 2. Ed. São Paulo: Cengage Learning, 2013.

SILVA, L. M. Contabilidade governamental: um enfoque administrativo da nova contabilidade pública. 8. ed. São Paulo: Atlas, 2009.

SILVA, M. C.; TAVARES, A. L.; ARAUJO, A. O.; SILVA, J. D. G. Análises de balanços públicos: quociente do resultado orçamentário do governo federal. 2000 2009. Revista Contabilidade Vista \& Revista, ISSN 0103-734X, Universidade Federal de Minas Gerais, 15, Belo Horizonte, v. 24, n. 3, p.15-34, jul./set. 2013.

SILVA, M. C.; SILVA, J. D. G.; BORGES, E. F. Análise de componentes principais para elaborar índices de desempenho no setor público. Rev. Bras. Biom., São Paulo, v.33, n.3, p.291-309, 2015.

SILVA, M. C.; SILVA, J. D. G. Avaliação de desempenho de governos municipais brasileiros na execução orçamentária da despesa por funções de governo. Revista Perspectivas Contemporâneas, v. 12, n. 1, p. 214-236, jan./abr. 2017.

SILVA, M. C.; SILVA, R. A.; SILVA, J. D. G. Análise e avaliação de políticas públicas: aspectos conceituais. Boletim de Administração Pública e Gestão Municipal, n. 61, outubro de 2016, p. 1434 - 1444. 
SOARES, M.; LYRA, R. L. W. C.; HEIN, N.; KROENKE, A. O emprego da análise de balanços e métodos estatísticos na área pública: o ranking de gestão dos municípios catarinenses. RAP - Rio de Janeiro, 45(5):1425-443, Set./out. 2011.

STEVENSON, W. J. Estatística aplicada à administração. São Paulo: Harper \& Row do Brasil, 1981.

TIMM, N. H. Applied multivariate analysis. New York: Springer-Verlag, 2002.

VIEIRA, A. S. Utilização de informações contábeis governamentais para análise da eficiência de políticas sociais dos municípios alagoanos. 2009. 190 f. Dissertação (Mestrado) - Programa de Pós-graduação em Ciências Contábeis, Universidade Federal de Pernambuco, Recife, 2009.

VYAS, S.; KUMARANAYAKE, L. Constructing socio-economic status indices: how to use principal components analysis. Health Policy and Planning, 9 October 2006, 21 (6): 459-468. DOI: 10.1093/heapol/czl029.

ZUCATTO, L. C.; SARTOR, U.; BEBER, S.; WEBER, R. Proposição de indicadores de desempenho na gestão pública. ConTexto, Porto Alegre, v. 9, n. 16, $2^{\circ}$ semestre 2009. 